\title{
Cirrus cloud-temperature interactions in the tropical tropopause layer: a case study
}

\author{
J. R. Taylor ${ }^{1}$, W. J. Randel ${ }^{1}$, and E. J. Jensen ${ }^{2}$ \\ ${ }^{1}$ National Center for Atmospheric Research, Atmospheric Chemistry Division, Boulder, CO, USA \\ ${ }^{2}$ NASA Ames Research Center, Earth Science Division, Moffett Field, CA, USA \\ Received: 5 April 2011 - Published in Atmos. Chem. Phys. Discuss.: 24 May 2011 \\ Revised: 10 September 2011 - Accepted: 22 September 2011 - Published: 6 October 2011
}

\begin{abstract}
Thin cirrus clouds in the Tropical Tropopause Layer (TTL) have important ramifications for radiative transfer, stratospheric humidity, and vertical transport. A horizontally extensive and vertically thin cirrus cloud in the TTL was detected by the Cloud Aerosol LIDAR and Infrared Pathfinder Satellite Observations (CALIPSO) on 27-29 January 2009 in the Tropical Eastern Pacific region, distant from any regions of deep convection. These observations indicate that the cloud is close to $3000 \mathrm{~km}$ in length along the CALIPSO orbit track. Measurements over this three day period indicate that the cloud event extended over a region from approximately $15^{\circ} \mathrm{S}$ to $10^{\circ} \mathrm{N}$ and $90^{\circ} \mathrm{W}$ to $150^{\circ} \mathrm{W}$ and may be one of the most extensive cirrus events ever observed. Coincident temperature observations from the Constellation of Observing Satellites for Meteorology, Ionosphere, and Climate (COSMIC) suggest that the cloud formed in-situ as a result of a cold anomaly arising from a midlatitude intrusion. The event appears to last for up to 2 days and the temperature observations do not show any indication of the expected infrared heating. It is hypothesized that the cloud could be maintained by either nucleation of numerous small ice crystals that don't sediment or by multiple localized ice nucleation events driven by temperature variability at scales smaller than the overall cloud field, producing small icecrystal sizes which have sufficiently long residence times $(\approx 53 \mathrm{~h})$ to maintain the cloud. It is possible that the residence times are augmented by vertical motion which could also act to offset the expected infrared heating. Further observations of similar events will be required in order to conclusively explain this curious cloud.
\end{abstract}

Correspondence to: J. R. Taylor

(taylor@ucar.edu)

\section{Introduction}

Cirrus clouds have been predicted and observed in the Tropical Tropopause Layer (TTL) for almost $30 \mathrm{yr}$ (Robinson, 1980; Winker and Trepte, 1998; Fueglistaler, 2009). TTL cirrus are typically thin lamina, with low optical depths. These thin, often subvisible clouds can have optical depths of less than 0.03 (Sassen and Cho, 1992) and are the most common form of cloud in the TTL (Wang and Dessler, 2006). Due to their transient nature and complex morphology, the climate impacts of TTL cirrus are poorly understood (Stubenrauch et al., 2007). These clouds are also of interest because of their influence on dehydration in the TTL and ultimately on stratospheric humidity (Gettelman et al., 2002; Jensen et al., 2001, 1996).

The formation of cirrus clouds in the TTL can be categorized into two different mechanisms: convection related generation, and in-situ formation (Pfister et al., 2001). Deep convective clouds with expanded anvil tops can have thin cirrus clouds detrain into the TTL. In contrast, the formation of in-situ cirrus can occur away from convection when a cold temperature anomaly causes the air to become saturated (or supersaturated). The cold anomaly may be caused by any number of mechanisms, such as gravity waves (Pfister et al., 2001), Kelvin waves (Boehm and Verlinde, 2000), mid-latitude intrusions (Waugh and Polvani, 2000) and large scale uplift (Corti et al., 2006). On average, over the equatorial region, sub-visible cirrus clouds occur $30 \%$ of the time (Mace et al., 2009). Over the Western Pacific, where TTL cirrus most frequently occur (Wang et al., 1996), Massie et al. (2002) showed that half of the TTL cirrus are associated with deep convection while the other half are formed in-situ. Regardless of how TTL cirrus are formed, their vertical thickness is typically less than $1 \mathrm{~km}$ and their horizontal scale is commonly less than $100 \mathrm{~km}$ (Massie et al., 2010).

Published by Copernicus Publications on behalf of the European Geosciences Union. 
Some TTL cirrus clouds have been seen with lifetimes as long as a few days (Winker and Trepte, 1998). The mechanism that is responsible for maintaining cirrus in the TTL for such a long period of time is not well understood. Boehm (1989) used a 2-D cloud resolving model to show that internal circulation is insufficient to maintain TTL cirrus and concluded that externally forced large-scale uplift must be required. Lilly (1988) used theoretical arguments to suggest that local radiative heating can induce uplift that sufficiently prevents the cloud-ice from sedimenting and consequently maintains the cloud. More recently, Durran et al. (2009) used a 2-D dynamical model to confirm Lilly's hypothesis and further suggest that adiabatic cooling assists in offsetting the induced diabatic warming. The dynamical model used by Durran et al. (2009) was extended by Dinh et al. (2010) to include ice microphysics (deposition growth, sublimation, and sedimentation). They showed that if TTL cirrus ice crystals are relatively small (radii $\leq 5 \mu \mathrm{m}$ ), then cloud radiative heating can generate a circulation with rising inside the cloud, sinking outside the cloud, entrainment at cloud base, and detrainment at cloud top. Dinh et al. (2010) showed that this circulation can provide a water supply for the cloud and substantially extend the cloud lifetime. It should be noted that available observations suggest that TTL cirrus ice crystals are considerably larger than $5 \mu \mathrm{m}$ (Lawson et al., 2008; Davis et al., 2010).

Radiative heating in TTL cirrus is a significant component in the TTL thermal budget (Corti et al., 2006; Yang et al., 2010). Radiative transfer calculations have shown that in the absence of underlying anvil cirrus, the radiative heating in TTL cirrus (dominated by infrared radiation) is a few $\mathrm{K} \mathrm{day}^{-1}$ (Jensen et al., 1996; McFarquhar et al., 2000; Comstock et al., 2002). Direct observations of heating rates in TTL cirrus at $\simeq 13-15 \mathrm{~km}$ with optical depths ranging from $0.01-0.1$ (mean of 0.034) indicated values of about 2.5$3.2 \mathrm{~K} \mathrm{day}^{-1}$, in good agreement with the calculated values (Bucholtz et al., 2010). Hartmann et al. (2001) showed that if thin TTL cirrus overlies optically thick anvil cirrus, the thin cirrus will radiatively cool the TTL. However, comparing satellite observations of isolated tropical cirrus with those that have underlying thick clouds showed that there was not a significant difference in optical depths of the cirrus (Riihimaki and McFarlane, 2010). Consistent with these observations, Yang et al. (2010) showed that the effects of solar heating are minimal on TTL cirrus and infrared heating is dominant. The effects of radiation ultimately influence upwelling and troposphere-to-stratosphere transport and, consequently, stratospheric humidity (Corti et al., 2006).

Global climatologies of cirrus clouds developed from satellite observations show that tropical $\left(20^{\circ} \mathrm{S}-20^{\circ} \mathrm{N}\right)$ cirrus cloud fraction is predominantly over the continents and Western Pacific (30\%-40\%) (Fu et al., 2007). Sassen et al. (2009) used similar observations to show that tropical clouds have an occurrence minimum over the Eastern Pacific in boreal winter. Satellite observations also show a large diurnal signal in TTL cloud occurrence, but this has little effect upon the low occurrence frequencies in the Eastern Pacific (Liu and Zipser, 2009).

Here we provide a case study of a clearly isolated, extensive cirrus cloud found in the TTL over the Eastern Pacific in a region devoid of deep convection in January 2009. We use CALIPSO observations to characterize the spatial and temporal extent of the cloud and its optical properties. Coincident high vertical resolution temperature observations from GPS radio occultation measurements are used to investigate the interaction between the cloud and background temperature field. Finally, these observations are presented in the context of the current theoretical understanding of cirrus physical properties and apparent inconsistencies are discussed.

\section{Observations}

Observations of cirrus clouds are provided by the CloudAerosol Lidar with Orthogonal Polarisation (CALIOP) instrument on board the Cloud Aerosol Lidar and Infrared Pathfinder Satellite Observations (CALIPSO) satellite. These are combined with temperature observations made by the Constellation of Observing Satellites for Meteorology, Ionosphere, and Climate (COSMIC) satellite system. Coincident observations made by these instruments elucidate details of cloud-temperature interaction in the TTL.

\subsection{CALIPSO Data}

The CALIPSO satellite mission was launched in April 2006 and is flying in formation with the A-train Constellation of Satellites (Stephens et al., 2002). This constellation is in a $705 \mathrm{~km}$ sun-synchronous polar orbit inclined at $98.2^{\circ}$ which yields a 16 day repeat cycle (Winker et al., 2009). The time of the observations is at $01: 30 \mathrm{~h}$ and $13: 30 \mathrm{~h}$, local time. The CALIOP instrument is a dual wavelength $(532 \mathrm{~nm}$ and $1064 \mathrm{~nm}$ ), polarization-sensitive LIDAR with a near-nadir viewing geometry (Winker et al., 2007). Over the $8-20 \mathrm{~km}$ altitude range, the charge-coupled device detector is configured to observe a small footprint of $\approx 1 \mathrm{~km}$ with a vertical resolution of $\approx 60 \mathrm{~m}$. For this study, the version 2.2 data product horizontally averaged into $5 \mathrm{~km}$ footprints is used (referred to as the $5 \mathrm{~km}$ Cloud Layer product) (Vaughan et al., 2004). In this product, the vertical cloud information is defined by cloud layer tops and bottoms only. The layer integrated attenuated backscatter is used to determine the optical depth of a given layer. Similarly, the layer integrated depolarization ratio is employed to determine the shape of the scattering particles and, consequently, assist in discriminating between phases in an observed cloud-layer. For example, a depolarization ratio of $\approx 0.4$ is indicative of ice-phase clouds, such as high-level cirrus clouds in the TTL (Hu, 2007). 


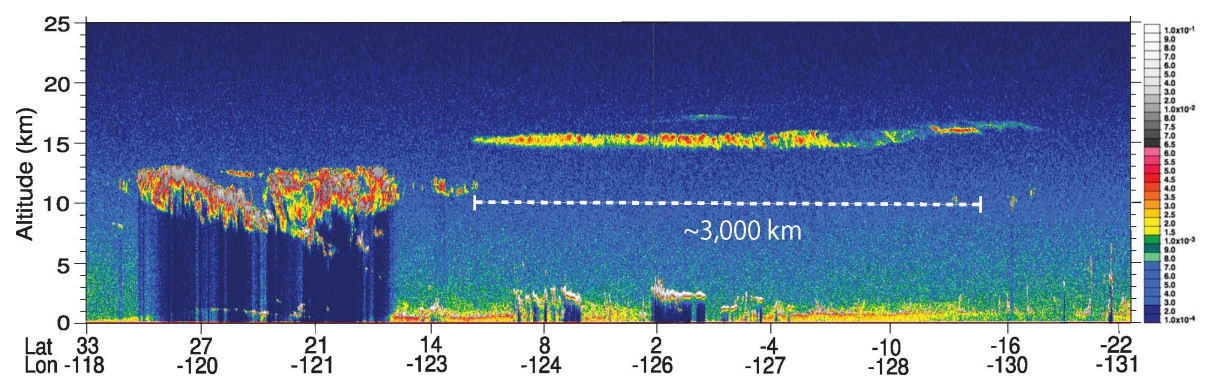

Fig. 1. Extensive cirrus cloud observed by CALIPSO on 28 January 2009 at approximately 10:00 UTC. The cloud extended from approximately $\left(12^{\circ} \mathrm{N}, 123^{\circ} \mathrm{W}\right)$ to $\left(15^{\circ} \mathrm{S}, 129^{\circ} \mathrm{W}\right)$. The image shows the CALIOP lidar vertical profile backscatter along the orbit track.

Cloud observations from CALIPSO have been used extensively to understand the climatology and statistics of cirrus clouds in the TTL (Fu et al., 2007; Mace et al., 2009). Furthermore, CALIPSO has been used in concert with other satellite sensors to successfully investigate specific case/process studies in the TTL (Takashima et al., 2010). The $5 \mathrm{~km}$ Cloud Layer product has been used to distinguish between TTL cirrus clouds that are related to convection versus those that are isolated (Riihimaki and McFarlane, 2010). Unfortunately, the limited spatial and temporal sampling of CALIPSO have proven challenging for observing single cirrus clouds as consecutive daytime/nighttime passes are separated by $\approx 25^{\circ}$ longitude at the equator with a time difference of $\approx 1.6$ hours between orbits (Virts et al., 2010). Despite these limitations, CALIPSO cloud observations can be combined with COSMIC temperature observations to provide sequential snapshots of cloud-temperature interactions.

\subsection{COSMIC data}

The COSMIC satellite system was launched in April 2006 as a joint project with the Taiwanese Formosa Satellite Mission 3 (FORMOSAT-3). The system consists of six microsatellites in a circular, $72^{\circ}$ inclination orbit at $512 \mathrm{~km}$ altitude (Anthes et al., 2008). Each satellite carries a Global Positioning System-Radio Occultation (GPS-RO) receiver that measures the phase delay of radio waves received from the constellation of GPS satellites as they are occulted by the Earth's atmosphere. From this phase delay, high resolution vertical profiles of precise bending angles are obtained (Kuo et al., 2004). These bending angles are then converted to measurements of temperature in the stratosphere and temperature and water vapor in the troposphere (Kursinski et al., 1997). The efficacy of this technique has previously been demonstrated by the CHAllenging Minisatellite Payload (CHAMP) (Wickert et al., 2001) and the Satellite de Aplicaciones CientificasC (SAC-C) (Hajj et al., 2004).

COSMIC observations are distributed around the globe with a temporal frequency as high as 2500 measurements/day (Schreiner et al., 2007). Because the occultations are measured between the six microsatellites and the GPS constella- tion, the temporal sampling does not follow a regular pattern although the orbit results in a higher sampling at mid/high latitudes. In this study, the Dry Profile observations (referred to as "dryPrf" product) are used and provide accurate observations of temperature above $10 \mathrm{~km}$ (Wickert et al., 2004). Although the profiles are provided on a $200 \mathrm{~m}$ grid, the vertical temperature resolution is closer to $1 \mathrm{~km}$ (Barnett et al., 2008). Comparisons between COSMIC and radiosondes above $10 \mathrm{~km}$ have shown that the mean difference in temperature observations is close-to-zero with virtually no day/night bias (He et al., 2009).

\section{Results}

An isolated, horizontally extensive, and vertically thin cirrus cloud in the TTL was detected by CALIPSO on 27-29 January 2009 in the Tropical Eastern Pacific region. At it's most extensive, observations indicate that the cloud is close to $3000 \mathrm{~km}$ in length along the CALIPSO orbit track, extending from approximately $15^{\circ} \mathrm{S}$ to $10^{\circ} \mathrm{N}$ (Fig. 1 shows the $532 \mathrm{~nm}$ lidar backscatter). Although the cloud vertical profile varies from orbit to orbit, the cloud appears to only be $\approx 500-700 \mathrm{~m}$ thick, extending from $\approx 15-15.7 \mathrm{~km}$ altitude in Fig. 1. Detailed along-track measurements of this cloud at $15.4 \mathrm{~km}$ are shown in Fig. 2. Across the entire cloud, the integrated attenuated backscatter is nearly identical at both wavelengths of the CALIOP LIDAR. This results in a color ratio of close to unity, which is expected for cirrus clouds composed of ice crystals much larger than the CALIOP observation wavelengths (Tao et al., 2008). Similarly, the depolarization ratio is almost constant at 0.4 , indicating that the cloud is comprised of ice-particles ( $\mathrm{Hu}, 2007)$. Although the optical depth varies across the cloud, it is primarily $<0.1$, confirming that this is indeed a thin cirrus cloud. Figure 2 does not show evidence of coherent small-scale spatial structure (e.g. wave-like activity) embedded throughout the entire $3000 \mathrm{~km}$ cirrus cloud.

The observations from CALIPSO (snapshots along the orbital tracks) were used to identify the space-time structure of this extensive cirrus event. A compilation of observations 

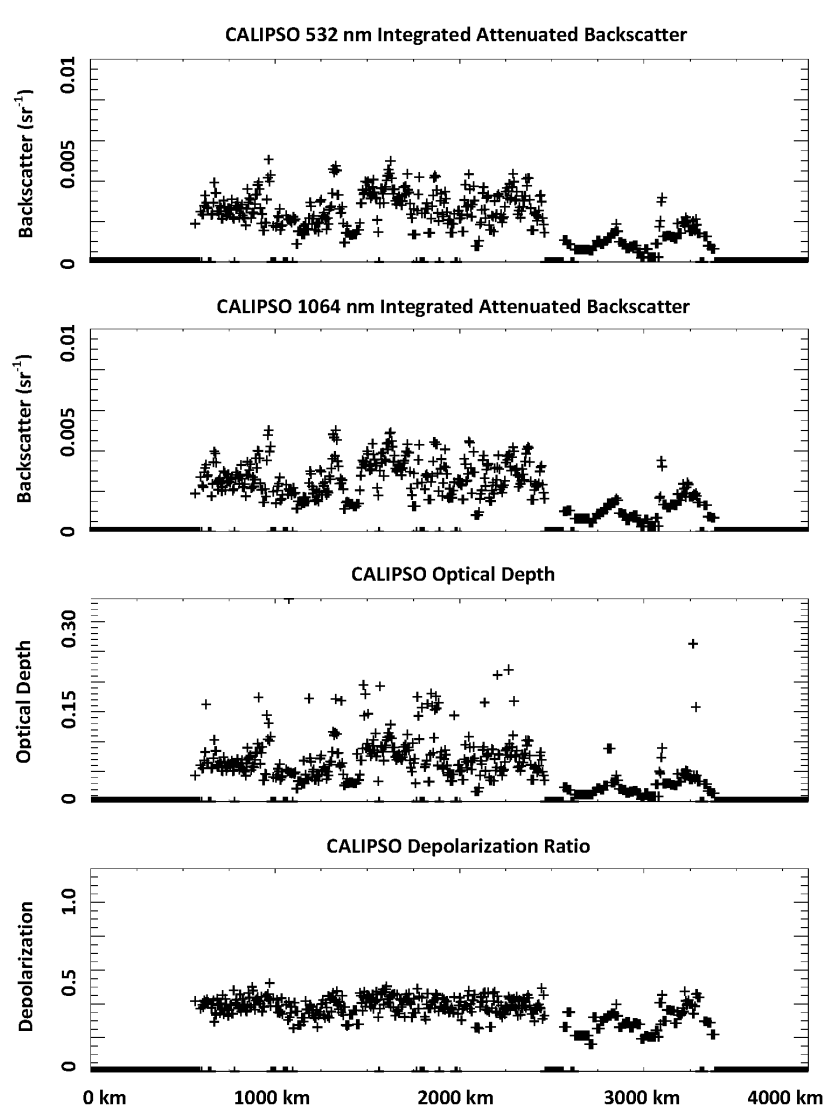

Fig. 2. Variation of the cirrus cloud parameters retrieved from CALIPSO at $15.5 \mathrm{~km}$, for the cloud shown in Fig. 1. The $\mathrm{x}$-axis represents the horizontal distance along the cloud from North to South (scale: 1 unit $=5 \mathrm{~km}$ ).

over this three day period suggests that the cloud covers approximately $90^{\circ} \mathrm{W}$ to $150^{\circ} \mathrm{W}$ and have no underlying clouds in the $5-13 \mathrm{~km}$ range (see Fig. 3). Because there are no other observations of this area during this three day period, it is impossible to determine whether the cloud extends between all of the orbital tracks. As the observations appear to not always be continuous along the tracks, it is likely that the optical thickness of the cloud sufficiently decreases in some regions, resulting in a "patchy" appearance. It is also possible that the cloud may migrate toward the west with time, but this may merely be an artifact of the sparse sampling projected upon the evolution of the cloud.

The daily altitude distribution of the observations of this cloud over 27-29 January 2009 are shown in Fig. 4. CALIPSO along-track $(5 \mathrm{~km})$ observations are counted within $200 \mathrm{~m}$ vertical bins, with cloud counts in the Eastern Pacific between $90^{\circ} \mathrm{W}$ to $150^{\circ} \mathrm{W}$ and $20^{\circ} \mathrm{S}$ to $15^{\circ} \mathrm{N}$ totaling 1013, 1571, and 548 on 27, 28, and 29 January 2009, respectively (i.e. the occurrences seen in Fig 4). The approximate peak altitudes of the normalized distributions are at $15.2 \mathrm{~km}, 15.4 \mathrm{~km}$, and $16.0 \mathrm{~km}$ on 27,28 , and 29 January, respectively. It is of interest to note that these are well below

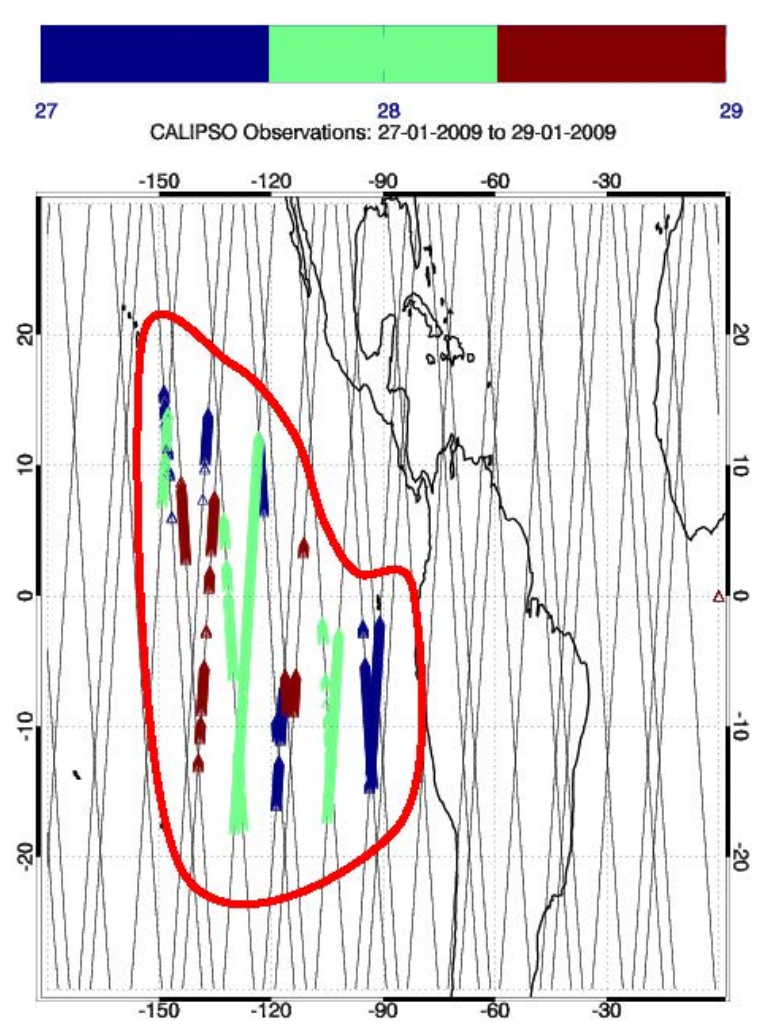

Fig. 3. The horizontal extent of the isolated TTL cirrus cloud over 27-29 January 2009. Colors indicate the presence of a cirrus cloud over altitudes $13-18 \mathrm{~km}$, with no clouds from $5-13 \mathrm{~km}$. Blue, green,and red symbols represent observations on the 27,28 , and 29 January, respectively. The cloud shown in Figs. 1 and 2 can be seen in the middle of the region (long, continuous, green track), extending continuously from $\approx 15^{\circ} \mathrm{S}$ to $\approx 10^{\circ} \mathrm{N}$

the cold point tropopause $(17.2 \mathrm{~km})$. Due to the considerable orbit to orbit variability in cloud altitude, the approximate full-width and half-maximum (FWHM) of the observed altitude distributions are $1.7 \mathrm{~km}, 1.7 \mathrm{~km}$, and $1.1 \mathrm{~km}$ on these respective days. The vertical shift in these daily distributions could suggest that the cloud is slowly moving upward over its lifetime. However, an alternative explanation is that the lower portion of the cloud is slowly sedimenting over the course of the three day period, resulting in an apparent vertical shift and the altitude distribution becoming narrower.

To assist in understanding the evolution of this tropical cirrus cloud, coincident observations from COSMIC were used to monitor the background temperature conditions. Coincidences were defined as occurring on the same day within the same region of the Eastern Pacific: $90^{\circ} \mathrm{W}$ to $150^{\circ} \mathrm{W}$ and $20^{\circ} \mathrm{S}$ to $15^{\circ} \mathrm{N}$ (see Fig. 5). Due to the orbital geometry and configuration of the radio occultation measurements, COSMIC has an irregular sampling pattern that makes temporal coincidence definition difficult. As such, all temperature observations within the region on a given day were included (there are typically 50 observations day ${ }^{-1}$ ). 


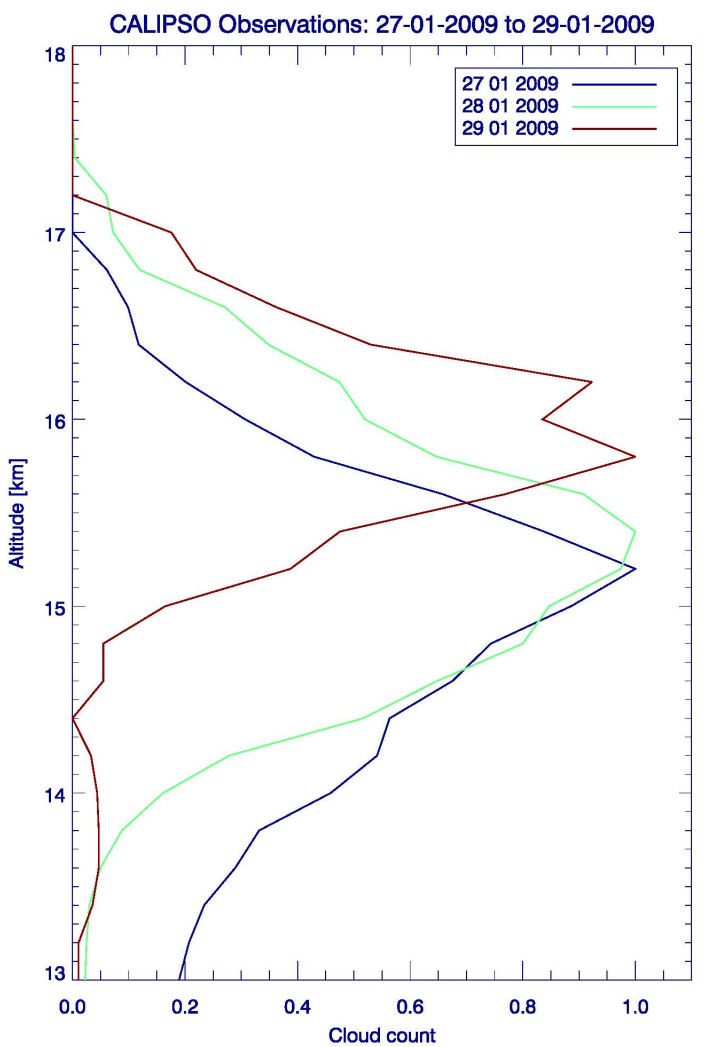

Fig. 4. Normalized distribution of cloud altitudes detected by CALIPSO in the Eastern Pacific on 27-29 January 2009. The distribution is determined from the CALIPSO $5 \mathrm{~km}$ Cloud Layer product (v2.2). Between the cloud base and cloud top, a cloud is counted every $200 \mathrm{~m}$ for each day of observations within the cloud outline from Fig. 3. For comparison, the peak count is normalized to 1 for each day.

A height-time section of daily temperature anomalies observed within this region is shown in Fig. 6. Anomalies were determined by subtracting the monthly mean temperature profile within this region and then calculating the daily mean difference. Figure 6 shows a cold anomaly of approximately 2-3 K occurs from 25-31 January 2009, spanning altitudes $15-18 \mathrm{~km}$, roughly coincident with the cloud occurrence. The average temperature in this region, over this time period, is approximately $191 \mathrm{~K}$. The 3 day duration of the observed cirrus cloud lies in the middle for this 6 day cold anomaly and is consistent with the timing of the coldest temperatures. It is of interest to note that the cloud appears at 15$15.5 \mathrm{~km}$ altitude, while anomalies at the cold point $(\approx 17 \mathrm{~km})$ are $2 \mathrm{~K}$ colder than at this altitude. It is also interesting to note that the temperatures directly below the cloud $(14 \mathrm{~km}$ and lower) are anomalously warm and are likely tied to the dynamical structure of the event (as discussed below).

The longitudinal distribution of daily-mean temperature anomalies on 28 January (see Fig. 7) confirms the localized nature of this anomaly. The cold anomaly is restricted to
COSMIC observations over $[-20,15]$; $[-150,-90]$; $12 \mathrm{~h}+/-12$ hours

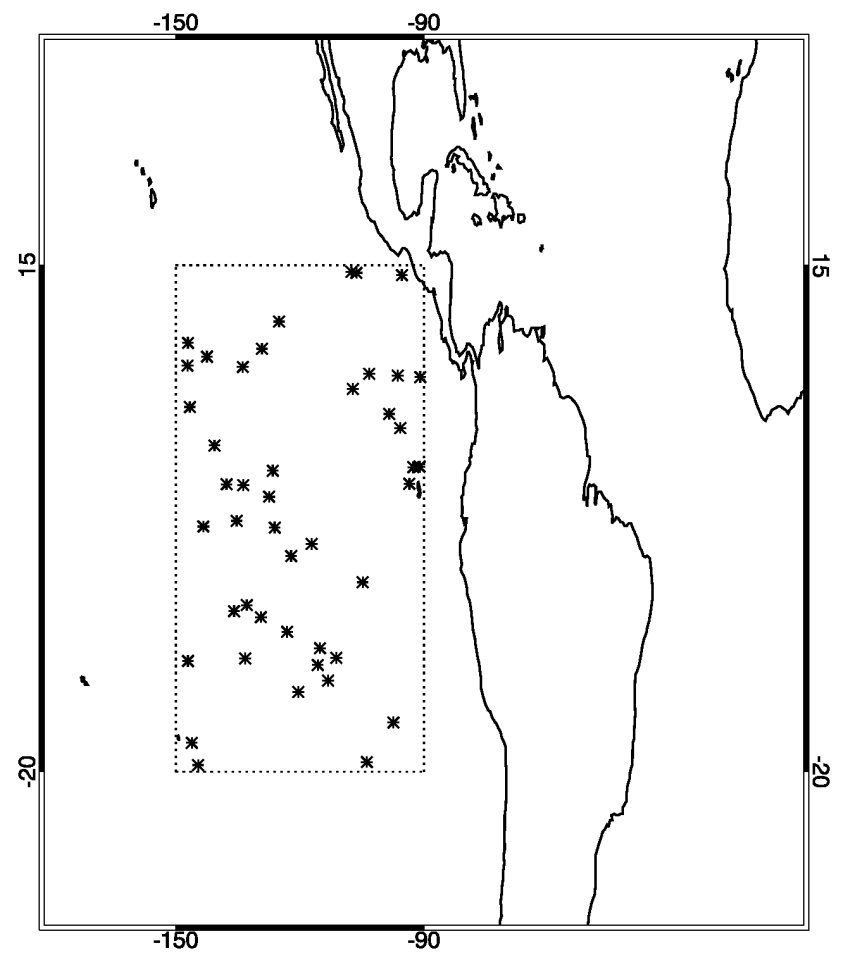

Fig. 5. COSMIC observations coincident with the area of the cirrus cloud on 28 January 2010

the Eastern Pacific region with a persistent warm anomaly present directly below. This vertical temperature structure can arise from balanced flow about an isolated (anticyclonic) potential vorticity anomaly (Hoskins et al., 1985). The horizontal structure of temperature anomalies at $16 \mathrm{~km}$ over 27-29 January is shown in Fig. 8. This structure highlights that the cold temperature anomalies in the Eastern Pacific $\left(90^{\circ} \mathrm{W}\right.$ to $130^{\circ} \mathrm{W}$ are linked with patterns in the subtropics; note the minimum near $15^{\circ} \mathrm{S}$ ). This behaviour is distinct from equatorially-centered temperature anomalies linked to equatorially-trapped waves, such as the Kelvin wave pattern seen over longitudes $\approx 0^{\circ}-120^{\circ} \mathrm{E}$ in Figs. 78 (Randel and $\mathrm{Wu}, 2005$, e.g.). The overall latitudinal and vertical structure of the Eastern Pacific temperature anomaly is more consistent with dynamical features originating in extratropics, extending into tropical latitudes, such as are often observed in the Eastern Pacific (Waugh and Polvani, 2000). The dynamical behavior during January 2009 is illustrated via the potential vorticity (PV) maps for the upper troposphere $(200 \mathrm{hPa})$ derived from NCEP reanalysis shown in Fig. 9, for time periods prior to (10-23 January) and during (27-29 January) the cloud event. The period of 10-23 January was characterized by persistent cyclonic PV patterns extending into the tropics in the Eastern Pacific from both the Northern Hemisphere $(\mathrm{NH})$ and Southern Hemisphere 


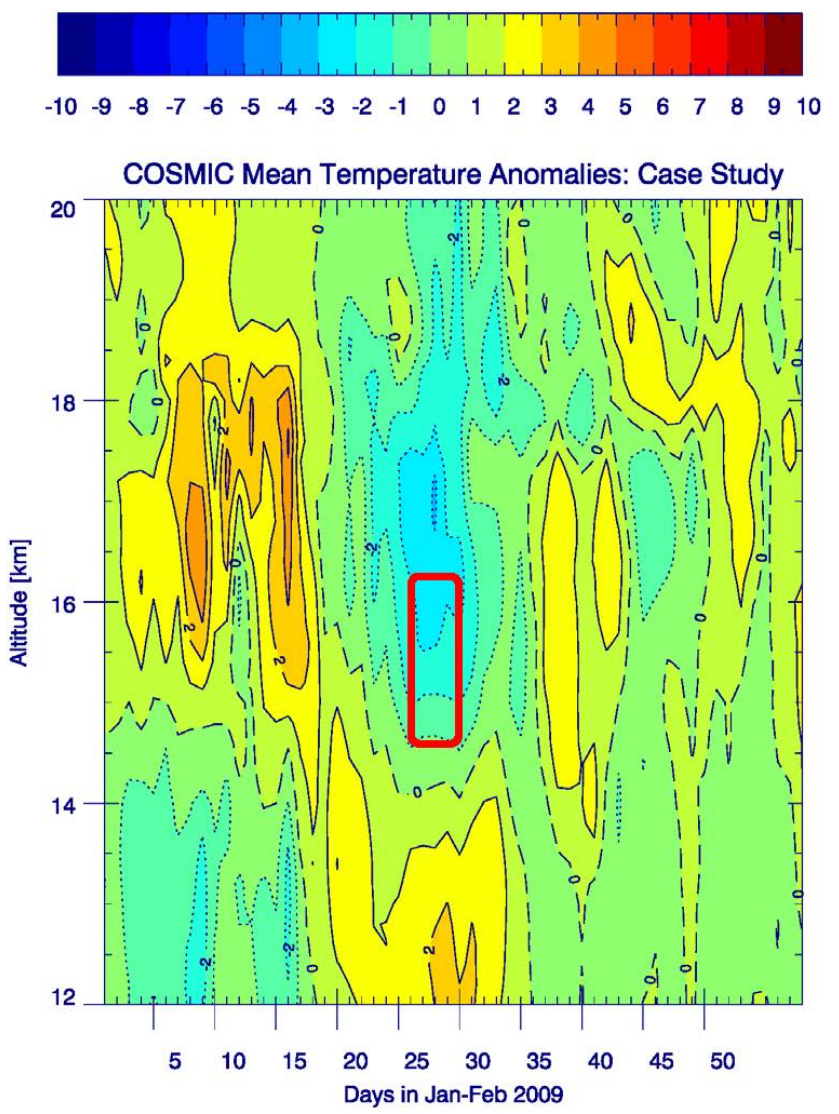

Fig. 6. Timeseries of daily mean temperature anomalies observed by COSMIC within the area of coincidence. Anomalies are derived by subtracting the monthly mean temperature within the area.

Average cold point temperatures over this period are below $190 \mathrm{~K}$.

(SH) that are associated with an equatorially-centered westerly wind maximum in this region. This structure changed over a few days during 24-28 January, wherein the SH intrusion moved westward and extended across the equator into the $\mathrm{NH}$, and the $\mathrm{NH}$ intrusion extended into the $\mathrm{SH}$. In the Eastern Pacific region of the cirrus cloud (boxed region in Fig. 9), the resulting PV anomalies for 27-29 January were anti-cyclonic compared to the persistent pattern earlier in the month, consistent with the balanced temperature structure of warm anomalies in the troposphere and cold anomalies in the lower stratosphere (seen in Fig. 7). Hence the cold temperatures and cloud formation occurred in concert with the dynamical evolution seen in Fig. 9.

The circulation in the region of the cloud was studied based on NCEP reanalysis winds. The evolution of $150 \mathrm{hPa}$ winds (the approximate pressure level of the cloud) during the six day cold period indicate that this region was relatively stagnant at this time. Calculated trajectories of air parcels within the cloud observed on 28 January 2009 (see Fig. 1) were seen to only move $\approx 200 \mathrm{~km}$ over 2 days. The only fresh air that comes into this region is at the extreme south-

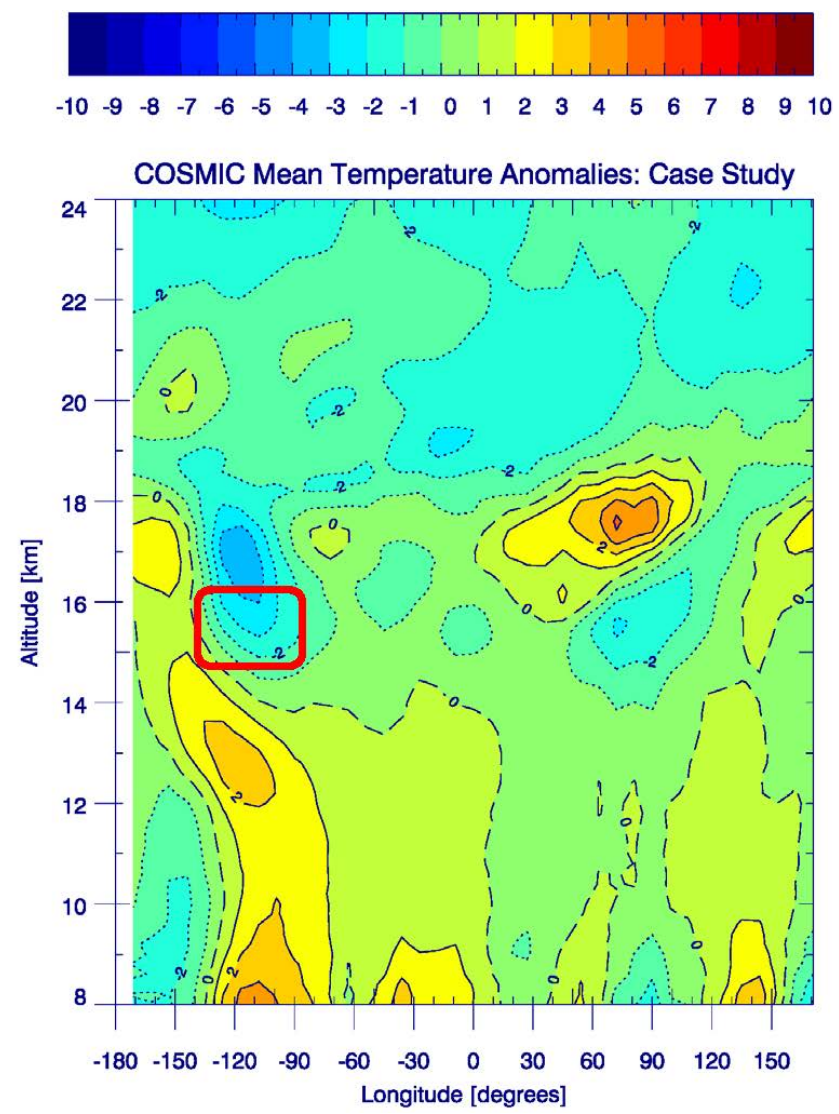

Fig. 7. Temperature anomalies as a function of longitude on $28 \mathrm{Jan}-$ uary 2010 over $15^{\circ} \mathrm{N}-15^{\circ} \mathrm{S}$. Anomalies are derived by subtracting the monthly mean temperature over the same latitude band.

ern end of the cloud; south of $\approx 17^{\circ} \mathrm{S}$. In Fig. 1, this portion of the cloud is somewhat different from the rest of the cloud, possibly due to the in-mixing of fresh air.

\section{Discussion}

We hypothesize that the cirrus cloud formed in situ when the circulation change seen in Fig. 9 resulted in a relative cold anomaly in the Eastern Pacific TTL. The decrease in temperature caused the air in this region to become supersaturated and the cirrus cloud formed. This is consistent with the coldest temperatures, and longest anomaly, occurring coincident with the cloud (Fig. 6). It is of interest to note that the cloud does not form in the coldest part of the TTL (the cold point, near $17 \mathrm{~km}$ ) but approximately $1-2 \mathrm{~km}$ below this area, which is consistent with the statistical behavior of clouds in this region (Fueglistaler, 2009). The lower altitude of the cloud is consistent with the COSMIC temperature anomalies (Figs. 6-7), while the mechanism limiting the cloud thickness is uncertain (although likely linked to the vertical structure of water vapour in this region). The apparent vertical motion suggested in Fig. 4 may simply be an artifact caused 


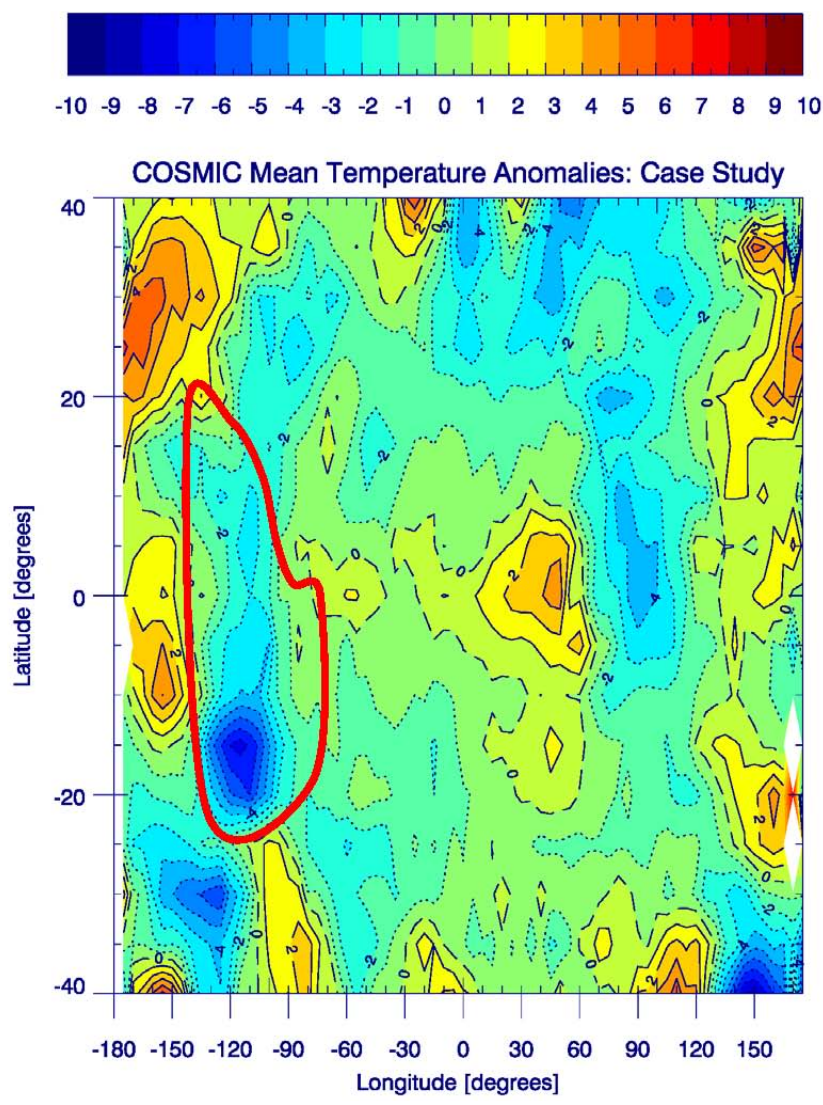

Fig. 8. Temperature anomalies on 27-29 January 2010 on the $16 \mathrm{~km}$ altitude surface. Anomalies are derived by subtracting the monthly mean temperature.

by sedimentation/sublimation at lower altitudes and higher altitude variations near the 0.003 optical depth sensitivity threshold of CALIPSO. Perhaps most surprising is the lack of observed temperature perturbation associated with the cloud (i.e. a lack of warming in the cloud layer). The anticipated heating rates of $2-3 \mathrm{~K} \mathrm{day}^{-1}$ (Hartmann et al., 2001) produce no observable signature in the COSMIC temperature timeseries, vertical structure, or horizontal field, although close coincidences in space and time are limited by the CALIPSO and COSMIC observations.

To the best of the authors' knowledge, a cirrus cloud of this extent and duration has never been observed before. Previous observations have found thin tropical cirrus clouds with an extent as large as $1000 \mathrm{~km}$ (Winker and Trepte, 1998) and an area as large as $100000 \mathrm{~km}^{2}$ (Peter et al., 2003), but nothing near as large as the cloud investigated here. Cirrus clouds in the TTL have estimated average lifetimes of $\approx 12 \mathrm{~h}$ (Jensen et al., 2011) and, even the most exceptional cases, only last up to $40 \mathrm{~h}$ (Luo and Rossow, 2004). The primary limitations on cloud lifetime are TTL temperature variability and the rate of ice crystal sedimentation into subsaturated air.
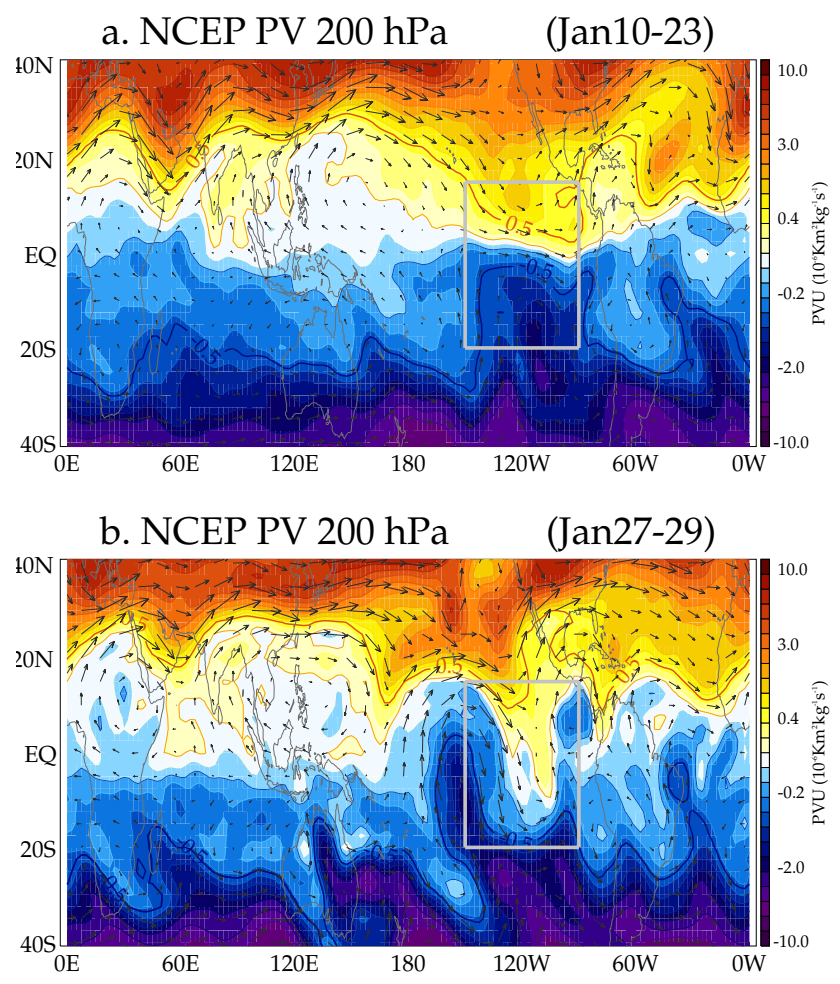

Fig. 9. $200 \mathrm{hPa}$ potential vorticity anomaly maps derived from NCEP reanalysis for time periods prior to (10-23 January) and during (27-29 January) the cloud event. The box highlights the region of the observed cloud and the vectors represent the associated wind field.

There are two hypotheses that can potentially explain the long lifetime of this cloud: (1) the cooling associated with the dynamical evolution could result in the formation of small ice crystals with exceptionally low fall speeds, or (2) the cloud region is in a state of dynamic flux in which there is continuous or sporadic generation of new ice crystals that subsequently grow and sediment through the cold layer. The first hypothesis can be investigated by estimating ice crystal radius based on the assumption of a monodispersed size distribution that is uniform throughout the cloud depth:

$r=\sqrt{\frac{\tau}{N_{o} \Delta z Q_{\mathrm{e}} \pi}}$,

where $r$ is the ice crystal effective radius, $\tau$ is the cloud optical depth, $N_{o}$ is the number concentration, $Q_{\mathrm{e}}$ is the extinction efficiency, and $\Delta z$ is the vertical cloud thickness (Comstock et al., 2002). For the small crystals likely to exist in optically thin cirrus, sedimentation speed can be calculated from the Stokes equation (Pruppacher and Klett, 1997). Assuming an average optical depth of 0.1 and a constant extinction efficiency of 2 , the average ice crystal radii, fall speeds, and estimated fall times for various number concentrations are shown in Tables 1 and 2. For conditions with high number concentration and small effective radii, ice crystals have 
Table 1. Estimates of effective ice crystal radius $(r)$, subsequent fall speeds $\left(v_{o}\right)$, and the time required to fall through the thickness of the cloud $t_{\Delta z}$. Calculations are made for three different number concentrations $\left(N_{o}\right)$ and assume a cloud thickness $(\Delta z)$ of $700 \mathrm{~m}$.

\begin{tabular}{cccc}
\hline$N_{o}\left[\right.$ number $\left.\mathrm{cm}^{-3}\right]$ & $r[\mu \mathrm{m}]$ & $v_{o}\left[\mathrm{~cm} \mathrm{~s}^{-1}\right]$ & $t_{\Delta z}[$ hours $]$ \\
\hline 0.1 & 15 & 3.5 & 5.6 \\
0.4 & 7.5 & 0.92 & 21 \\
1.0 & 4.7 & 0.37 & 53 \\
\hline
\end{tabular}

a residence time as large as $53 \mathrm{~h}$ for a $700 \mathrm{~m}$ thick cloud and $27 \mathrm{~h}$ for a $500 \mathrm{~m}$ thick cloud. The temperature anomalies shown in Fig. 6 suggests that the onset of cooling was rapid in this region. Such high ice concentrations could be produced by homogeneous freezing of aqueous sulfate aerosols if the cooling is sufficiently rapid (Karcher and Lohmann, 2002). Based on the vertical thickness of the cloud shown in Fig. 1, it is plausible that the ice crystals are sufficiently small to result in residence times of over 2 days. This is consistent with the gravity-wave-driven ascent hypothesis for cloud maintenance proposed by Dinh et al. (2010) but it is unlikely that these ice crystals are as small as those used in their model. Given the limitations of the observations, it is challenging to quantitatively address the second hypothesis; in all likelihood, there is some degree of dynamic flux achieved over a portion of this region.

Alternative hypotheses require some form of sustained vertical motion to maintain the cloud at this altitude. Recent results from a three dimensional cloud-resolving model show that low thermal stability $\left(\mathrm{N}^{2}<0.009\right)$ allows the radiative heating to induce sufficient small-scale convection to maintain the cloud at a persistent high altitude (Jensen et al., 2011). Although conditions of low thermal stability do occur in the TTL, it is near-impossible to have uniformly low stability throughout this entire region of the Eastern Pacific. Results from a column model used to simulate conditions for extensive clouds observed in the Indian Ocean showed that an upwelling of $\approx 5 \mathrm{~mm} \mathrm{~s}^{-1}$ below the tropopause is required to sustain the cloud (Luo et al., 2003). The apparent two-day shift in peak altitude from Fig. 4 is $\approx 4.6 \mathrm{~mm} \mathrm{~s}^{-1}$. It is challenging to interpret this shift as apparent upward motion of the cloud because the altitude distribution varies from orbit to orbit and, even for small ice crystals (a few microns), the sedimentation speed is comparable to updraft speeds. While this value is consistent with the proposed mechanism for cloud maintenance, it is unlikely that upwelling would occur in this region. The downward portion of the Walker Cell dominates the large-scale circulation over the Eastern Pacific and clear sky radiative heating calculations suggest near-zero vertical motion near $15 \mathrm{~km}$ (Yang et al., 2010, e.g.,).

While the first hypothesis of small ice-crystals having a long residence time may explain the long duration of the cloud, it does not address the lack of temperature perturba-
Table 2. Same as Table 1 but for a cloud thickness $(\Delta z)$ of $500 \mathrm{~m}$.

\begin{tabular}{cccc}
\hline$N_{o}\left[\right.$ number $\left.\mathrm{cm}^{-3}\right]$ & $r[\mu \mathrm{m}]$ & $v_{o}\left[\mathrm{~cm} \mathrm{~s}^{1}\right]$ & $t_{\Delta z}$ [hours] \\
\hline 0.1 & 17 & 4.5 & 3.1 \\
0.4 & 8.9 & 1.3 & 11 \\
1.0 & 5.6 & 0.52 & 27 \\
\hline
\end{tabular}

tion that would be expected from longwave heating. There has been a previous attempt to model fixed heating with no resulting temperature perturbation (Bretherton and Smolarkiewicz, 1989), but this yielded extensive buoyancy displacements and no such signatures are apparent in the COSMIC temperature field. As the trajectory analysis indicates that the horizontal winds are nearly stagnant over this region, there is no obvious source of fresh moisture to stimulate the growth of new ice crystals. Therefore, some mechanism must be responsible for inhibiting sedimentation into subsaturated air below. If the apparent vertical shift in the cloud is due to sustained upwelling, this would not only inhibit sedimentation, it would mean that the cloud would move through a background average temperature of $\approx 200 \mathrm{~K}$ at $15 \mathrm{~km}$ to $\approx 195 \mathrm{~K}$ at $16 \mathrm{~km}$. This change of $5 \mathrm{~K}$ could be central to masking a longwave heating signal.

While there are a number of caveats associated with this speculation (the limited sensitivity of CALIPSO, the imprecision of the altitude distributions, the notion of large-scale sustained upwelling in the TTL over the Eastern Pacific), this hypothesis does provide a plausible explanation for the 2-3 day lifetime of the cloud and the lack of response in the temperature field.

\section{Conclusions}

Variations in the large-scale circulation linked with tropical intrusions generated an anomalously cold region in the tropical tropopause layer over the Eastern Pacific on 26-31 January 2009. In this region, which is characterized by a lack of deep convection, one of the largest, most extensive cirrus clouds ever observed persisted from 27-29 January 2009. This cirrus occurred in a thin layer of order $1 \mathrm{~km}$ thick in the area covering $90^{\circ} \mathrm{W}$ to $150^{\circ} \mathrm{W}$ and $20^{\circ} \mathrm{S}$ to $15^{\circ} \mathrm{N}$ over an altitude of $\approx 15-15.5 \mathrm{~km}$. The CALIOP LIDAR on board the CALIPSO satellite indicated that the cirrus cloud is composed of ice-particles and varied in optical depth between $\approx 0.003$ and $\approx 0.21$. Over the two-three day lifetime of the cloud, the altitude distribution changes and the peak altitude appears to ascend from $15.2 \mathrm{~km}$ to $16.0 \mathrm{~km}$. Although isolated TTL cirrus typically have calculated heating rates close to $3 \mathrm{~K} \mathrm{day}^{-1}$, coincident observations made by the COSMIC satellite system do not reveal any associated warming in the temperature field. 
The lifetime of TTL cirrus clouds is typically $\approx 12 \mathrm{~h}$ and is limited by ice-crystal growth and sedimentation into subsaturated air below the cloud layer. The cloud described here persists in the TTL for $\approx 2$ days with no sign of sedimentation or descent. The mechanism responsible for maintaining the cloud over this large area for so long is not well understood. A previously proposed mechanism for maintaining long-lived cirrus relies on sustained vertical upwelling of $\approx 5 \mathrm{~mm} \mathrm{~s}^{-1}$, a value that is consistent with the observed change in altitude distributions. Furthermore, the change in altitude coincides with a background temperature change of $\approx 5 \mathrm{~K}$, which could mask the temperature perturbation that would be expected from cloud-induced heating. Although this provides a consistent explanation of the observations, it is unlikely to be realistic as the calculated clear-sky vertical velocity around $15 \mathrm{~km}$ is near zero.

This case study provides an important test of microphysics models and our understanding of cirrus cloud physics. Unfortunately, precise measurements of vertical upwelling are not available for correlative comparison. Without access to more details, these curious observations await further investigation.

Acknowledgements. The authors wish to thank the CALIPSO and COSMIC Science Teams for providing cloud and temperature data, respectively. We thank Charles Bardeen, Steven Massie, Darryn Waugh, and Fei Wu for discussions and comments on the manuscript. We especially thank Mijeong Park at NCAR for producing the PV maps in Fig. 9. This work is partially supported by the NASA GNSS program. The National Center for Atmospheric Research is sponsored by the National Science Foundation.

Edited by: D. J. Cziczo

\section{References}

Anthes, R. A., Bernhardt, P. A., Chen, Y., Cucurull, L., Dymond, K. F., Ector, D., Healy, S. B., Ho, S.-P., Hunt, D. C., Kuo, Y.-H., Liu, H., Manning, K., McCormick, C., Meehan, T. K., Randel, W. J., Rocken, C., Schreiner, W. S., Sokolovskiy, S. V., Syndergaard, S., Thompson, D. C., Trenberth, K. E., Wee, T.-K., Yen, N. L., and Zeng, Z.:The COSMIC/FORMOSAT-3 Mission: Early Results, Bull. Am. Meteorol. Soc., 89, 313-333, doi:10.1175/BAMS-89-3-313, 2008.

Barnett, J. J., Hepplewhite, C. L., Osprey, S., Gille, J. C., and Khosravi, R.: Cross-validation of HIRDLS and COSMIC radiooccultation retrievals, particularly in relation to fine vertical structure, Proc. SPIE, 7082, 16-167, doi:10.1117/12.800702, 2008.

Boehm, H. P.: A general equation for the terminal fall speed of solid hydrometeors, J. Atmos. Sci., 46, 2419-2427, 1989.

Boehm, M. T. and Verlinde, J.: Stratospheric influence on upper tropospheric tropical cirrus, Geophys. Res. Lett., 27, 3209-3212, 2000.
Bretherton, C. S., and Smolarkiewicz, P. K.: Gracity waves, compensating subsidence, and detrainment around cumulous clouds, J. Atmos. Sci., 46, 740-759, 1989.

Bucholtz, A., Hlavka, D. L., McGill, M. J., Schmidt, K. S., Pilewskie, P., Davis, S. M., Reid, E. A., and Walker, A. L.: Directly measured heating rates of a tropical subvisible cirrus cloud, J. Geophys. Res., 115, D00J09, doi:10.1029/2009JD013128, 2010.

Comstock, J. M., Ackerman, T. P., and Mace, G. G.: Ground-based lidar and radar remote sensing of tropical cirrus clouds at Nauru Island: cloud statistics and radiative impacts, J. Geophys. Res., 107, 4714, doi:.10.1029/2002JD002203, 2002.

Corti, T., Luo, B. P., Fu, Q., Vmel, H., and Peter, T.: The impact of cirrus clouds on tropical troposphere-to-stratosphere transport, Atmos. Chem. Phys., 6, 2539-2547, doi:10.5194/acp-6-25392006, 2006.

Davis, S., Hlavka, D., Jensen, E., Rosenlof, K., Yang, Q., Schmidt, S., Borrmann, S., Frey, W., Lawson, P., Voemel, H., and Bui, T. P.: In situ and lidar observations of tropopause subvisible cirrus clouds during TC4, J. Geophys. Res., 115, D00J17, doi:10.1029/2009JD013093, 2010.

Dinh, T. P., Durran, D. R., and Ackerman, T.: The maintenance of tropical tropopause layer cirrus, J. Geophys. Res., 115, D02104, doi:10.1029/2009JD012735, 2010.

Durran, D. R., Dinh, T. P., Ammerman, M., and Ackerman, T.: The mesoscale dynamics of thin tropical tropopause cirrus, J. Atmos. Sci., 66, 2859-2873, 2009.

$\mathrm{Fu}, \mathrm{Q}$., Hu, Y., and Yang, Q.: Identifying the top of the tropical tropopause layer from vertical mass flux analysis and CALIPSO lidar cloud observations, Geophys. Res. Lett., 34, L14813, doi:10.1029/2007GL030099, 2007.

Fueglistaler, S., Dessler, A. E., Dunkerton, T. J., Folkins, I., Fu, Q., and Mote, P. W.: Tropical tropopause layer, Rev. Geophys., 47, RG1004, doi:10.1029/2008RG000267, 2009.

Gettelman, A., Randel, W. J., Wu, F., and Massie, S. T.: Transport of water vapor in the tropical tropopause layer, Geophys. Res. Lett., 29(01), 1009, doi:10.1029/2001GL013818, 2002.

Hartmann, D. L., Holton, J. R., and Fu, Q.:The heat balance of the tropical tropopause, cirrus, and stratospheric dehydration, Geophys. Res. Lett., 28(10), 1969, doi:10.1029/2000GL012833, 2001.

Hajj, G. A., Ao, C. O., Iijima, B. A., Kuang, D., Kursinski, E. R., Mannucci, A. J., Meehan, T. K., Romans, L. J., de la Torre Juarez, M., and Yunck, T. P.: CHAMP and SAC-C atmospheric occultation results and intercomparisons, J. Geophys. Res., 109, D06109, doi:10.1029/2003JD003909, 2004.

He, W., Ho, S.-P., Chen, H., Zhou, X., Hunt, D,. and Kuo, Y.-H.: Assessment of radiosonde temperature measurements in the upper troposphere and lower stratosphere using COSMIC radio occultation data, Geophys. Res. Lett., 36, L17807, doi:10.1029/2009GL038712, 2009.

Hoskins, B. J., McIntyre, M. E., and Robertson, A. W.: On the use and significance of isentropic potential vorticity maps, Q. J. Roy. Meteorol. Soc., 111, 877-946, 1985.

Hu, Y.: Depolarization ratioeffective lidar ratio relation: Theoretical basis for space lidar cloud phase discrimination, Geophys Res. Lett., 34, L11812, doi:10.1029/2007GL029584, 2007.

Jensen, E., Toon, O., Selkirk, H., Spinhirne, J., and Schoeberl, M.: On the formation and persistence of subvisible cirrus clouds near 
the tropical tropopause, J. Geophys. Res., 101, 21361-21375, 1996.

Jensen, E., Pfister, L., Ackerman, A., Tabazadeh, A., and Toon, O.: A conceptual model of the dehydration of air due to freezedrying by optically thin, laminar cirrus rising slowly across the tropical tropopause, J. Geophys. Res., 106, 17237-17252, 2001.

Jensen, E., Pfister, L., and Toon O.: Impact of radiative heating, wind shear, temperature variability, and microphysical processes on the structure and evolution of thin cirrus in the tropical tropopause layer, J. Geophys. Res., 116, D12209, doi:10.1029/2010JD015417, 2011.

Karcher, B. and Lohmann, U.: A parameterization of cirrus cloud formation: Homogeneous freezing of supercooled aerosols, J. Geophys. Res., 107, 4010, doi:10.1029/2001JD000470, 2002.

Kuo, Y.-H, Wee, T. K., Sokolovskiy, S., Rocken, C., Schreiner, W., Hunt, D., and Anthes, R.: Inversion and Error Estimation of GPS Radio Occultation Data, J. Meteorol. Soc. Jpn., 82, 507-531, 2004

Kursinski, E., Hajj, G., Schofield, J., Linfield, R., and Hardy, K.: Observing Earth's atmosphere with radio occultation measurements using the Global Positioning System, J. Geophys. Res., 102, 23429-23465, 1997.

Lawson, R. P., Pilson, B., Baker, B., Mo, Q., Jensen, E., Pfister, L., and Bui, P.: Aircraft measurements of microphysical properties of subvisible cirrus in the tropical tropopause layer, Atmos. Chem. Phys., 8, 1609-1620, doi:10.5194/acp-8-1609-2008, 2008.

Lilly, D.: Cirrus outflow dynamics, J. Atmos. Sci., 45, 1594-1605, 1988.

Liu, C. and Zipser, E. J.: Implications of the day versus night differences of water vapor, carbon monoxide, and thin cloud observations near the tropical tropopause, J. Geophys. Res., 114, D09303, doi:10.1029/2008JD011524, 2009.

Luo, B. P., Peter, Th., Wernli, H., Fueglistaler, S., Wirth, M., Kiemle, C., Flentje, H., Yushkov, V. A., Khattatov, V., Rudakov, V., Thomas, A., Borrmann, S., Toci, G., Mazzinghi, P., Beuermann, J., Schiller, C., Cairo, F., Di Don-Francesco, G., Adriani, A., Volk, C. M., Strom, J., Noone, K., Mitev, V., MacKenzie, R. A., Carslaw, K. S., Trautmann, T., Santacesaria, V., and Stefanutti, L.: Ultrathin Tropical Tropopause Clouds (UTTCs): II. Stabilization mechanisms, Atmos. Chem. Phys., 3, 1093-1100, doi:10.5194/acp-3-1093-2003, 2003.

Luo, Z. and Rossow, W. B.: Characterizing Tropical Cirrus Life Cycle, Evolution, and Interaction with Upper-Tropospheric Water Vapor Using Lagrangian Trajectory Analysis of Satellite Observations, J. Clim., 17, 4541-4563, 2004.

Mace, G. G., Zhang, Q., Vaughan, M., Marchand, R., Stephens, G., Trepte, C., and Winker, D.: A description of hydrometeor layer occurrence statistics derived from the first year of merged Cloudsat and CALIPSO data, J. Geophys. Res., 114, D00A26, doi:10.1029/2007JD009755, 2009.

Massie, S., Gettelman, A., Randel, W., and Baumgardner, D.: Distribution of tropical cirrus in relation to convection, J. Geophys. Res., 107, 4591, doi:10.1029/2001JD001293, 2002.

Massie, S. T., Gille, J., Craig, C., Khosravi, R., Barnett, J., Read, W., and Winker, D.: HIRDLS and CALIPSO observations of tropical cirrus, J. Geophys. Res., 115, D00H11, doi:10.1029/2009JD012100, 2010.

McFarquhar, G. M., Heymsfield, A. J., Spinhirne, J., and Hart, W.:
Thin and subvisual tropopause tropical cirrus: observations and radiative effects, J. Atmos. Sci., 57, 1841-1853, 2000.

Peter, Th., Luo, B. P., Wirth, M., Kiemle, C., Flentje, H., Yushkov, V. A., Khattatov, V., Rudakov, V., Thomas, A., Borrmann, S., Toci, G., Mazzinghi, P., Beuermann, J., Schiller, C., Cairo, F., Di Donfrancesco, G., Adriani, A., Volk, C. M., Strom, J., Noone, K., Mitev, V., MacKenzie, R. A., Carslaw, K. S., Trautmann, T., Santacesaria, V., and Stefanutti, L.: Ultrathin Tropical Tropopause Clouds (UTTCs): I. Cloud morphology and occurrence, Atmos. Chem. Phys., 3, 1083-1091, doi:10.5194/acp-3-1083-2003, 2003.

Pfister, L., Selkirk, H. B., Jensen, E. J., Schoeberl, M. R., Toon, O. B., Browell, E. V., Grant, W. B., Gary, B., Mahoney, M. J., Bui, T. V., and Hintsa, E.: Aircraft observations of thin cirrus clouds near the tropical tropopause. J. Geophys. Res., 106, 9765-9786, 10.1029/2000JD900648, 2001.

Pruppacher, H. R. and Klett, J. D.: Microphysics of Clouds and Precipitation. 2d ed. Kluwer Academic, 1997.

Randel, W. J. and Wu, F.: Kelvin wave variability near the equatorial tropopause observed in GPS radio occultation measurements, J. Geophys. Res., 110, D03102, doi:10.1029/2004JD005006, 2005.

Riihimaki, L. D. and McFarlane, S. A.: Frequency and morphology of tropical tropopause layer cirrus from CALIPSO observations: Are isolated cirrus different from those connected to deep convection?, J. Geophys. Res., 115, D18201, doi:10.1029/2009JD013133, 2010.

Robinson, G. D.: The transport of minor atmospheric constituents between troposphere and stratosphere, Q. J. Roy. Meteorol. Soc., 106, 227-253. doi:10.1002/qj.49710644802, 1980.

Sassen, K. and Cho, B. S.: Subvisual-Thin Cirrus Lidar Dataset for Satellite Verification and Climatological Research, J. Appl. Meteor., 31, 1275-1285, doi:10.1175/1520-0450(1992)031, 1992.

Sassen, K., Wang, Z., and Liu, D.: Cirrus clouds and deep convection in the tropics: Insights from CALIPSO and CloudSat, J. Geophys. Res., 114, D00H06, doi:10.1029/2009JD011916, 2009.

Schreiner, W., Rocken, C., Sokolovskiy, S., Syndergaard, S., and Hunt, D.: Estimates of the precision of GPS radio occultations from the COSMIC/FORMOSAT-3 mission, Geophys. Res. Lett., 34, L04808, doi:10.1029/2006GL027557, 2007.

Stephens, G., Vane, D. G., Boain, R. J., Mace, G. G., Sassen, K., Wang, Z., Illingworth, A. J., OConnor, E. J., Rossow, W. B., Durden, S. L., Miller, S. D., Austin, R. T., Benedetti, A., Mitrescu, C., and the CloudSat Science Team: The CLOUDSAT Mission and the A-Train: A New Dimension of Space-Based Observations of Clouds and Precipitation, B. Am. Meteorol. Soc., 83, 1771-1790, doi:10.1175/BAMS-83-12-1771, 2002.

Stubenrauch, C. J., Eddounia, F., Edwards, J. M., and Macke, A: Evaluation of Cirrus Parameterizations for Radiative Flux Computations in Climate Models Using TOVSScaRaB Satellite Observations, J. Climate, 20, 4459-4475, 2007.

Takashima, H., Eguchi, N., and Read W.': A short-duration cooling event around the tropical tropopause and its effect on water vapor, Geophys. Res. Lett., 37, L20804, doi:10.1029/2010GL044505, 2010.

Tao, Z., McCormick, M. P., Wu, D., Liu, Z., and Vaughan, M. A.: Measurements of cirrus cloud backscatter color ratio with a twowavelength lidar, Appl. Opt., 47, 1478-1485, 2008. 
Vaughan, M. A., Young, S. A., Winker, D. M., Powell, K. A., Omar, A. H., Liu, Z., Hu, Y., and Hostetler, C. A.: Fully automated analysis of space-based lidar data: An overview of the CALIPSO retrieval algorithms and data products, Proc. SPIE Int. Soc. Opt. Eng., 5575, doi:10.1117/12.572024, 2004.

Virts, K. S., Wallace, J. M., Fu, Q, and Ackerman, T. P.: Tropical Tropopause Transition Layer Cirrus as Represented by CALIPSO Lidar Observations, J. Atmos. Sci., 67(10), 31133129, doi:10.1175/2010JAS3412, 2010.

Wang, L. and Dessler, A. E.: Instantaneous cloud overlap statistics in the tropical area revealed by ICESat/GLAS data, Geophys. Res. Lett., 33, L15804, doi:10.1029/2005GL024350, 2006.

Wang, P.-H., Minnis, P., McCormick, M. P., Kent, G. S., and Skeens, K. M.: A 6-year climatology of cloud occurrence frequency from Stratospheric Aerosol and Gas Experiment II observations (1985-1990), J. Geophys. Res., 101, 29407-29429, doi:10.1029/96JD01780, 1996.

Waugh, D. W. and Polvani, L. M.: Climatology of intrusions into the tropical upper troposphere, Geophys. Res. Lett., 27, 38573860, 2000.

Winker, D. M. and Trepte, C. R.: Laminar cirrus observed near the tropical tropopause by LITE, Geophys. Res. Lett., 25, 33513354, 1998.
Winker, D. M., Hunt, W. H., and McGill, M. J.: Initial performance assessment of CALIOP, Geophys. Res. Lett., 34, L19803, doi:10.1029/2007GL030135, 2007.

Winker, D. M., Vaughan, M. A., Omar, A., Hu, Y., Powell, K. A., Liu, Z., Hunt, W. H., and Young, S. A.: Overview of the CALIPSO Mission and CALIOP Data Processing Algorithms, J. Atmos. Oceanic. Technol., 26, 2310-2323, doi:10.1175/2009JTECHA1281.1, 2009.

Wickert, J., Reigber, C., Beyerle, G., Konig, R., Marquardt, C., Schmidt T., Grunwaldt L., Galas R., Meehan, T. K., Melbourne, W. G., and Hocke, K.: Atmosphere sounding by GPS radio occultation: First results from CHAMP, Geophys. Res. Lett., 28, 3263-3266, 2001.

Wickert, Schmidt, T., Beyerle, G., Knig, R., Reigber, C., Jakowski, N.: The radio occultation experiment aboard CHAMP: Operational data analysis and validation of vertical atmospheric profiles, J. Meteor. Soc. Japan, 82-, 381-395, 2004.

Yang, Q., Fu, Q., and Hu, Y.: Radiative impacts of clouds in the tropical tropopause layer, J. Geophys. Res., 115, D00H12, doi:10.1029/2009JD012393, 2010. 